\title{
Characterization, fractionation, and functional properties of Acacia oerfota gum
}

\author{
MUSTAFA ELOBIED AHMED, MOHAMMED ELMUBARK OSMAN", ELFATIH AHMED HASSAN \\ College of Science, Sudan University of Science and Technology. P.O. Box 407, Khartoum, Sudan
}

Manuscript received: 24 December 2020. Revision accepted: 13 March 2021.

\begin{abstract}
Ahmed ME, Osman ME, Hassan EA. 2021. Characterization, fractionation, and functional properties of Acacia oerfota gum. Asian J Trop Biotechnol 18: 1-12. Thirty gum samples were collected at two locations around Senga and Wadel Hadad, Sudan during 2015. Fifteen samples of Acacia oerfota were taken from each location. For the fifteen samples, four composite samples were made for each position by mixing. Chemical, physicochemical, rheological behavior, distribution of molecular weight and molecular weight, and emulsification properties of $A$. oerfota gum were all performed. The results show the range for moisture content (11.8-13.1\%), protein percentage (2.19-3.93\%), tannin (268-292 ppm), acid equivalent weight (2941-5357), total uronic acid percentage (3.62-6.60\%). The percentage of Senga's cationic composition was calcium 0.287 , potassium 0.131 , strontium 0.004 , and iron 0.010 . While the percentage of Wadel Hadad had a caionic composition of calcium 0.242, potassium 0.145, strontium 0.005, sulphur 0.002, and iron 0.001. The rheological actions of $A$. oerfota gum demonstrates Newtonian conduct (when applied stress is removed, the molecular form is restored). For the two composite sites of Senga and Wadel Hadad, oerfota gum varied between 1.68x105 and 1.80x105 g/mol respectively. The molecular weight was determined by gel permeation chromatography (GPC-MALLS). This was 6.23x105 g/mole and 9.59x 105 g/mole for the two sites. Samples of A. oerfota gum obtained from the Senga location indicate three fractions; Arabinogalactan protein (AGP) with a molecular weight of $1.11 \%$ by $4.77 \times 105$ mass and $\mathrm{Rg} 50 \%$. The second and third fractions (Arabinogalactan AG + Glycoprotein GP) were 5.76x105 g/mole molecular weight, 98.89 percent mass. For A, GPC-MALLS. An AGP with a molecular weight of 4.19x105, percent mass 0.84 , and $\mathrm{Rg} 187$ is shown by A. oerfota gum samples obtained from Wadel Hadad. The second and third fractions had a molecular weight of $8.24 \times 105 \mathrm{~g} /$ mole, 99.16 percent mass (AG + GP). Both emulsions exhibit broad droplet size, displaying a standard distribution of bimodal droplet size with a pronounced shoulder representing weak uniformity and unstable emulsions.
\end{abstract}

Keywords: Acacia oerfota, characterization, fractionation

\section{INTRODUCTION}

The species Acacia, commonly known as acacia, thorn tree, whistling thorn, or wattle, is a genus of shrubs and trees. There are approximately 1300 species in the genus Acacia, of which about 960 are native to Australia, with the remainder spread across the tropical to warm-temperate regions of both hemispheres, including Africa, Asia, and the Americas (Smith and Figueiredo 2011).

Sudan is endowed with the largest ranging species, such as Acacia senegal (Hasab) Acacia seyal (Talha), Acacia polyacantha (Kakamut); Acacia laeta (Shubahi); Acacia mellifere (Kitir), Acacia oerfota (Lao't), Acacia sieberiana (Kuk). There are more than 30 Acacia species, the vast majority of which are gum species (Elamin 1990; Abdel Nour 1999).

Gums have a high molecular weight hydrophilic polysaccharides, typically with colloidal properties that can dissolve or swell in a suitable solvent to create gels or highly viscous suspension. Therefore, the term gum is applied to a wide range of gum characteristic substances and cannot be precisely described. Hydrophobic compounds sometimes referred to as gums, are hydrocarbons and other petroleum products with high molecular weight, rubbers, some synthetic polymers, trendy for chewing gum, and resinous saps that sometimes exude from evergreens, often commercially tapped, such as gum balsam and gum resin (Anderson and Cree 1968).
The objectives of this research were (i) to classify Acacia oerfota gum by investigating the general properties of the gum physiochemically; (ii) to perform the comparison and contrast of A. oerfota gum's physicochemical characteristics with Acacia senegal gum and Acacia seyal, as well as (iii) to examine: $A$. oerfota gum's rheological behavior, molecular weight and distribution of molecular weight, and A. oerfota gum's emulsifying properties.

\section{MATERIALS AND METHODS}

\section{Sample collection}

In February 2015, gum of A. oerfota samples were collected from two locations, namely Senga City Blue Nile State and Wadel Hadad Aljazeera State (15 samples from each location) (Table 1 and Figure 1). 10 samples were collected from each position (sample/tree) and 5 samples were collected ( 3 trees/sample). By making incisions of about $15 \mathrm{vcm}$ long and $3 \mathrm{~cm}$ wide using an axe, many $A$. oerfota trees were tapped. There were 10 to 20 blazes on the branches of the trees. 


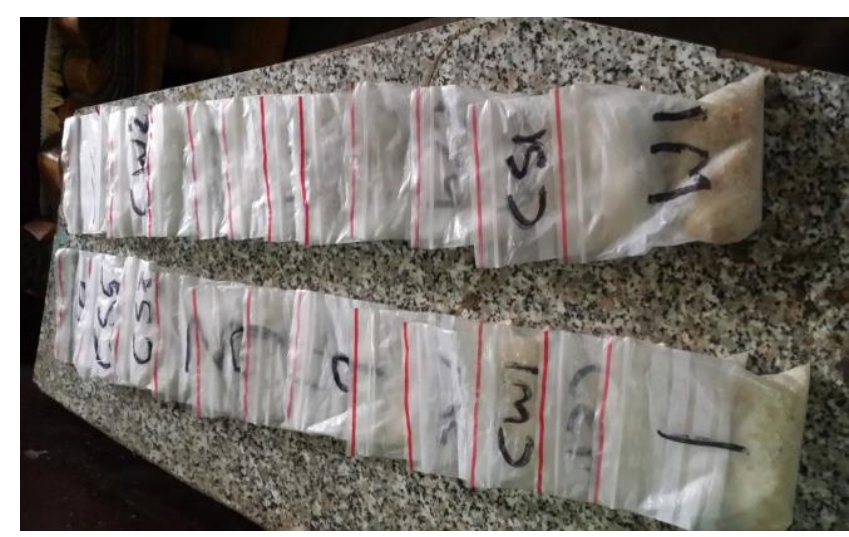

Figure 1. Gum oerfota samples.

Table 1. Samples code and location of A. oerfota gum (Collection date February 2015).

\begin{tabular}{|c|c|c|c|}
\hline \multicolumn{2}{|c|}{ Wadel Hadad location } & \multicolumn{2}{|c|}{ Senga location } \\
\hline No. & Code & No. & Code \\
\hline 1 & Sample.1 & 20 & Sample.16 \\
\hline 2 & Sample. 2 & 21 & Sample.17 \\
\hline 3 & Sample. 3 & 22 & Sample.18 \\
\hline 4 & Sample.4 & 23 & Sample.19 \\
\hline 5 & Sample. 5 & 24 & Sample.20 \\
\hline 6 & Sample.6 & 25 & Sample.21 \\
\hline 7 & Sample.7 & 26 & Sample.22 \\
\hline 8 & Sample. 8 & 27 & Sample.23 \\
\hline 9 & Sample.9 & 28 & Sample.24 \\
\hline 10 & Sample.10 & 29 & Sample. 25 \\
\hline 11 & Sample.11 & 30 & Sample.26 \\
\hline 12 & Sample.12 & 31 & Sample. 27 \\
\hline 13 & Sample.13 & 32 & Sample. 28 \\
\hline 14 & Sample.14 & 33 & Sample.29 \\
\hline 15 & Sample.15 & 34 & Sample.30 \\
\hline 16 & Comp.1 & 35 & Comp.5 \\
\hline 17 & Comp. 2 & 36 & Comp.6 \\
\hline 18 & Comp.3 & 37 & Comp.7 \\
\hline 19 & Comp.4 & 38 & Comp.8 \\
\hline
\end{tabular}

Note: Comp.1 prepared by mixing equal amount of (sample 1-4) Wadel Hadad. Comp. 2 prepared by mixing equal amount of (sample 5-10) Wadel Hadad. Comp.3 prepared by mixing equal amount of (sample11-15) Wadel Hadad. Comp.4 prepared by mixing equal amount of (sample 1-15) Wadel Hadad. Comp.5 prepared by mixing equal amount of (sample 1-5) Senga. Comp.6 prepared by mixing equal amount of (sample 6-10) Senga. Comp.7 prepared by mixing equal amount of (sample 11-15) Senga. Comp. 8 prepared by mixing equal amount of (sample 1-15) Senga.

\section{Purification of gum samples}

All of the gum samples were dried and washed by hand at room temperature to remove foreign particles. Using a mortar and pestle, the samples were then ground and kept for further examination in containers.

\section{Determination of physicochemical properties Moisture content}

The humidity content was calculated by FAO (1990). At $105^{\circ} \mathrm{C}$, one gram of ground gum was oven-dried to a steady weight. The sum of humidity was measured as the proportion of the weight loss to the original weight.
Moisture content $\%=($ Initial weight-final weight $) \times 100$ Initial weight

Total ash content

The total ash content was calculated by FAO (1990). Placed in a crucible, one gram of gum sample ignited in a muffle furnace at $550{ }^{\circ} \mathrm{C}$ for 5 hours. The estimation of total ash was as follows:

$$
\text { Total ash }(\%)=\frac{\mathrm{w}_{2} \times 100}{\mathrm{w}_{1}}
$$

Where:

$\mathrm{W}_{1}$ : Original weight of the sample,

$\mathrm{W}_{2}$ : weight of the sample after ignition

\section{$p H$}

Using the Berkman Zeromatic IV $\mathrm{pH}$ meter at room temperature, the $\mathrm{pH}$ of $1 \%$ aqueous solution of gum was determined.

\section{Specific optical rotation}

For the $1 \%$ aqueous gum solution, the observed optical rotation was determined using a Bellingham and Stanley polarimeter equipped with a sodium lamp and a cell with a path length of $20 \mathrm{~cm}$ at measurements, and the precise optical rotation was measured using the following equation:

Specific rotation $[\alpha]_{\mathrm{D}}^{\mathrm{T}}=[(\alpha \times 100) /(\mathrm{C} \times \mathrm{L})]$.
Where:
$\alpha$ : observed optical rotation
C : concentration of gum solution
D : sodium imitation line $=532 \mathrm{~nm}$
$\mathrm{T}$ : temperature
$\mathrm{L}$ : length of polarimeter tube in decimeters

\section{Viscosity measurements}

The viscosity of gum solution was measured using a Utube viscometer immersed in a water bath with a constant temperature set at $25 \mathrm{C}^{\circ}$. In $0.2 \mathrm{M} \mathrm{NaCl}$, gum solutions $(0.5 \%, 1 \%, 2 \%, 3 \%$, and $4 \%)$ were prepared, then filtered and transferred to the viscometer. Intrinsic viscosity has been defined by:

Relative viscosity $\left[\eta_{\text {rel }}\right]=\eta / \eta_{\circ}=\mathrm{t} / \mathrm{t}_{\circ}$

Specific viscosity $\left[\eta_{\mathrm{sp}}\right]=\eta_{\mathrm{rel}}-1$

Reduced viscosity $\left[\eta_{\text {red }}\right]=\eta_{\text {sp }} / C$

Intrinsic viscosity $\left.[\eta]=\lim _{\mathrm{c} \rightarrow 0} \eta_{\mathrm{sp}} / \mathrm{C}\right]$

The intrinsic viscosity $[\eta]$ is determined from the intercept in the plot of $\eta_{\text {reduced }}$ as a function of a sample concentration at zero concentration (infinite dilution). The inherent viscosity is determined from the intercept in the plot of $\eta_{\text {rel }} / \mathrm{c}$ as a function of a sample concentration at zero concentration (infinite dilution). 


\section{Calorific value}

The IKA C1 calorimeter system was calibrated by $1 \mathrm{~g}$ ( 2 Tabs) regular IKA C723 Benzoic acid tabs, with cal.val cross-section, $26461 \mathrm{~J} / \mathrm{g}, \quad \mathrm{RSD} 0.03 \%$, and LOT SZBD2180V. The temperature was $19 \mathrm{C}, 30$ bar gas pressure (oxygen) and had $2700 \mathrm{rpm}$ pump flow. The bag was then covered by rolling and placed in a decomposition vessel enclosed by a water jacket, weighing around $0.5 \mathrm{~g}$ of A. oerfota gum and placed in a small plastic bag that has a cross value of $46463 \mathrm{j} / \mathrm{g}$. In an oxygen atmosphere, the sample was combusted, and the calorific value of the sample was measured.

\section{Nitrogen and protein content}

The total nitrogen in gum samples was calculated according to AOACAC by the Kjeldahl method (1990). The process consists of three basic steps: step one, digestion of the samples with a catalyst in sulfuric acid resulting in the conversion of nitrogen to ammonia, step two, distillation of ammonia into a trapping solution, and step three, quantification of ammonia with a regular solution by titration. The reactions to these steps can be seen as follows:

$$
\begin{aligned}
& \text { Sample }+\mathrm{H}_{2} \mathrm{SO}_{4} \text { (conc.) }+\mathrm{Heat} \rightarrow\left(\mathrm{NH}_{4}\right)_{2} \mathrm{SO}_{4} \\
& \left(\mathrm{NH}_{4}\right)_{2} \mathrm{SO}_{4}+2 \mathrm{NaOH} \rightarrow 2 \mathrm{NH}_{3}+\mathrm{Na}_{2} \mathrm{SO}_{4}+2 \mathrm{H}_{2} \mathrm{O} \\
& \mathrm{NH}_{3}+\mathrm{H}_{3} \mathrm{BO}_{3} \rightarrow \mathrm{NH}_{4}^{+}+\mathrm{H}_{2} \mathrm{BO}_{3}^{-} \\
& \mathrm{H}_{2} \mathrm{BO}_{3}^{-}+\mathrm{HCl} \rightarrow \mathrm{H}_{3} \mathrm{BO}_{3}+\mathrm{Cl}^{-}
\end{aligned}
$$

\section{The method}

0.5 grams of each sample was weighed and transferred to Kjeldahl digestion flasks and a Kjeldahl tablet (copper sulfate-potassium sulfate catalyst) was applied to each. 10 cm3 concentrated, nitrogen-free, sulphuric acid was also added. The tube was then installed in the digestion heating system, which had previously been set to $240^{\circ} \mathrm{C}$ and capped with an aerated manifold. The solution was then heated at the above temperature until a strong pale yellowish-green color was observed. This signaled the completion of the digestion. The tubes were then allowed to reach room temperature. Their contents were moved quantitatively to the Kjeldahl distillation apparatus, followed by the addition of distilled water and $30 \%(\mathrm{w} / \mathrm{v})$ sodium hydroxide. Steam distillation began and the release of ammonia was absorbed by $25 \mathrm{~cm} 3$ of $2 \%$ boric acid. Back titration of the produced borate was then performed versus $0.02 \mathrm{M}$ of hydrochloric acid, using methyl red as an indicator. This was the same way with the blank titration.

\section{$\% \mathrm{~N}=\underline{14.01 \times \mathrm{M} \mathrm{x} \text { (volume of titrant-volume of blank) } \times 100}$ Weight of sample (grams)}

Where: $\mathrm{M}$ is the molarity of hydrochloric acid. Protein content was calculated using nitrogen conversion factor resulting from amino acid analysis as follows:\% protein $=\% \mathrm{~N} x 6.51$.

\section{Acid equivalent weight}

An Amberlite Resin IR (180H+) was packed with a column of glass. Once the resin was thoroughly washed with the acid, $\mathrm{HCl} 0.2 \mathrm{M}$ was transferred through the column. This was then accompanied by distilled water until the chloride-free column was $20 \mathrm{~cm} 3$ eluent equalize to one drop $0.1 \mathrm{~N} \mathrm{NaOH}$. The column was then passed through 50 $\mathrm{cm} 3$ of $3.0 \%$ gum solution, followed by purified water until $250 \mathrm{~mL}$ of the eluent and washing volume were obtained. This $250 \mathrm{~cm} 3$ of eluent is titrated against $\mathrm{NaOH}$ of $0.1 \mathrm{~N}$. The apparent equivalent acid weight was determined by means of:

Equivalent weight $=\underline{\text { Weight of the sample } \times 1000}$ Volume of liter x Molarity of alkali

\section{Total uronic acid}

Uronic acid was determined by multiplying the molecular weight of uronic acid (194) by 100 and dividing by the apparent equivalent weight of gum sample as follows:

Uronic acid $\%=\underline{194 \times 100}$

Eq. wt.

\section{Determination of total polyphenol (tannin\%)}

The tannin content was calculated based on the Prussian blue assay originally conceived by Price and Butler and subsequently adjusted (Graham 1992). The tannin content is taken to reflect the "total phenols" and more specifically, the "Gallic acid equivalents" as Gallic acid-99\% in purity purchased from Sigma Aldrich was used as an analytical criterion for the determination of hydrolyzable tannins. 500 $\mu \mathrm{g} / \mathrm{g}$ Gallic acid has been prepared in distilled water. This was then diluted in series to achieve a concentration of 400 , $300,200,100$ and $50 \mu \mathrm{g} / \mathrm{g}$ as normal. $0.10 \mathrm{~mL}$ of each sample or norm was dispensed in a universal $30 \mathrm{~mL} .3 \mathrm{~mL}$ of distilled water was applied by vortex mixing for $30 \mathrm{sec}$. Next $1.00 \mathrm{~mL}$ of $0.016 \mathrm{M}(0.526 \mathrm{~g} / 100 \mathrm{~mL}, \mathrm{w} / \mathrm{v})$ potassium hexacyano ferrate(III) $\left[\mathrm{K}_{3}[\mathrm{Fe}(\mathrm{CN}) 6]\right.$, followed by $1.00 \mathrm{~mL}$ of $0.02\left(0.324 \mathrm{gFeCl}_{3} / 100 \mathrm{~mL} \mathrm{~d} . \mathrm{w}+0.83 \mathrm{mLHCl}\right)$ ferric chloride $\left(\mathrm{FeCl}_{3}\right)$ were added and immediately mixed by vortex mixer for $30 \mathrm{sec}$. The stabilizer was prepared by a combination of 10.00 metric $\mathrm{mL}(85 \%)$ of $85 \%$ phosphoric acid $\left(\mathrm{H}_{3} \mathrm{PO}_{3}\right), 1.00 \mathrm{~mL}(1 \%)$ of arabic, $30 \mathrm{~mL}$ of distilled water, exactly after 15 min (Perkin Elmer Lambda XLS+, UV/ Vis's), in three versions, using an absorptive content, exactly 15 minutes after applying the reagent to the sample $5.00 \mathrm{~mL}$, and the vortex $30 \mathrm{~mL}$ of the distilling water. Instead of $A$. oerfota gum or gallic acid standards, solvents are prepared blank by using all reagents and solvent $0.1 \mathrm{~mL}$ instead. For all users of Perkin Elmer Lambda 40 UV/Vis spectroscopy, the absorbance was estimated at $700 \mathrm{~nm}$. The measurement error for both samples was less than $10 \%$ and the average.

\section{Determination of number average molecularweight by Osmotic pressure}

One hundred fifty micrometer of different concentrations $(0.25 \%, 0.5 \%, 1 \%, 1.5 \%, 2 \%, 2.5 \%$, and $3 \%)$ of $A$. oerfota gum samples were ejected into Osmometere 150 and the osmotic pressure was digital determined at $25^{\circ} \mathrm{C}$. The number average molecular weight determined using equation: 
The Intercept $\frac{\equiv \pi}{\mathrm{C} \rightarrow 0} \quad=\frac{\mathrm{RT}}{\mathrm{M}_{\mathrm{n}}}$

Where:

$\pi$ : osmotic pressure,

$\mathrm{R}$ : Gas constant,

$\mathrm{T}$ : Temperature,

$\mathrm{C}:$ Concentration,

Mn : Number average molecular weight.

\section{Rheological measurement}

$50 \% \mathrm{w} / \mathrm{w}$ of the $A$. oerfota gum solution (based on dry weight) was prepared in distilled water, then the solution was agitated overnight on a tube roller mixer (SRT9. Stuart Scientific, UK) to ensure that the sample dissolves and hydrates completely. The solutions were then centrifuged at a speed of $3000 \mathrm{rpm}$ for 10 minutes using a centrifuge (Megafuge 1.0R, Heraeus SEPATECH, Germany). One dilution was prepared from the stock solution $(25 \% \mathrm{w} / \mathrm{w})$ and re-refused to examine the rheological activity as a prior practice. Rheological measurements were carried out using the Malvern Series KINEXUS pro+ rheometer (Malvern Instruments Ltd., Malvern, Worcester, UK), equipped with a $40 \mathrm{~mm}$ cone diameter and a $20 \mathrm{~mm}$ angle cone and plate geometry. For gum solutions ranging from 10 to $50 \% \mathrm{w} / \mathrm{v}$, steady shear viscosity curves were determined both by shear rate ramp-up (from 0.01 to $10000 \mathrm{~s}-1$ ) and corresponding shear rate ramp-down (from 10000 back to $0.01 \mathrm{~s}-1)$. In the $0.1-10 \mathrm{~Hz}$ frequency range, dynamic rheological measurements were performed to determine the elastic module $\left(G^{\prime}\right)$, viscous module $\left(G^{\prime \prime}\right)$ and dynamic viscosity. The linear viscoelastic area, at $1 \mathrm{~Hz}$, was evaluated. Using a Peltier element, the temperature of the samples were regulated at $0.1 \mathrm{C}$. The control and data processing of the rheometer was performed using computer software.

\section{Molecular weight and molecular weight distribution Sample preparation}

Gum samples were prepared (based on dry weight) in 1 $\mathrm{mM}$ phosphate buffer at $\mathrm{pH} 7$ containing $0.2 \mathrm{M} \mathrm{NaCl}, 2.0$ $\mathrm{mg} / \mathrm{mL}$ followed by one dilution $(1.0 \mathrm{mg} / \mathrm{mL})$. Then they were hydrated by roller (SRT9. Stuart Scientific, UK) mixing the solution overnight to ensure that the sample was fully dissolved and hydrated. Using Megafuge 1.0R (Heraeus SEPATECH, Germany), the solutions were then centrifuged for 10 minutes at a speed of $3000 \mathrm{rpm}$. The gum solutions were then filtered prior to injection into the GPC-MALLS system using a $0.45-\mu \mathrm{m}$ nylon filter (Whatman, $13 \mathrm{~mm}$ ).

\section{GPC-MALLS}

Average molecule weight $(\mathrm{Mw})$ and molecular weight distribution analysis were done using various techniques such as Osmometere, gel permeation chromatography, were subjected to gum exudates from A. oerfota tree (GPCMALLS). The machine used was the Model 6000A Solvent Delivery System Waters (Division of Millipore, USA) connected to a column containing the Superose 6 (Amersham Biosciences) (10 x 300mm), Rheodyne Model
7125 manual syringe. Three detectors, the refractive index (RI) Wyatt Optilab DSP interferometric refractometer operated at $633 \mathrm{~nm}$ (Wyatt Technology Corporation, USA), the multi-angle laser light dispersion photometer DAWN EOS operated at $690 \mathrm{~nm}$ with $\mathrm{He}-\mathrm{Ne}$ laser (Wyatt Technology Corporation, USA) and the Agilent 1100 series G1314A UV detector were monitored (214 nm, Agilent Technologies). MALLS makes absolute molecular mass and gyration radius ( $\mathrm{Rg})$, and $\mathrm{UV}$ detects the protein components of the gum. RI provides a precise concentration profile (Katayama et al. 2006). Data was processed by the program Astra for Windows (version 4.90.07, Wyatt Technology Corporation).

\section{Emulsification properties of the gum \\ Emulsion preparation}

In a glass container, distilled water was applied to $8 \mathrm{~g}$ of the gum sample (based on dry weight) to give $40 \mathrm{~g}$ in total with a $20 \%$ (w/w) gum solution concentration. The specimen was mixed overnight on a roller mixer until the specimen was fully dissolved. For each sample (ranging from approximately 19.97 to approximately $20 \mathrm{~g}$ ), the exact measured grams of the prepared gum solution was filtered using $100 \mu \mathrm{m}$ mesh, then combined with $0.52 \mathrm{~mL}$ of $10 \%$ $(\mathrm{w} / \mathrm{v})$ sodium benzoate solution as a preservative. Next, $0.48 \mathrm{~mL}$ of $10 \%(\mathrm{w} / \mathrm{v})$ citric acid solution was added to change the $\mathrm{pH}$ to $4,15.71 \mathrm{~mL}$. Follwed by $15.73 \mathrm{~mL}$ of distilled water being added, before $4.2 \mathrm{~g}$ of ODO oil was applied. Using a POLYTRON homogenizer (PT 2100, KINEMA TICA AC) at $22000 \mathrm{rpm}$, the mixed solution was homogenized for 3 minutes. As a dispersing instrument, the Impeller (PTDA21 $9 \mathrm{~mm}$ tip diameter) was used. The preemulsified mixture was homogenized using a high-pressure NanoVater to achieve a small particle size $<1$ micron (NV30-FA, MITSUBISHI GOT1000.). It was passed twice at $75 \mathrm{MPa}$ to achieve effective disaggregation of the gum. The final emulsion was held in closed universal glass, and the particle size of the emulsion was measured. Then it was put it in the Vacuum Oven at 60oC (GALLENKAMP. OVA031.XX1.5). After 3 and 7 days, the droplet size was measured again.

\section{Droplet size analysis}

Using Mastersizer 3000, a laser diffraction particle size analyzer, the droplet size distribution of the emulsions was measured (Malvern Instruments). As a dispersant, distilled water was used and a value of 1.45 was used for the oil phase refractive index (ODO). After an accelerated stability test for 3 and 7 days, the emulsification stability of samples was maintained at $60 \mathrm{C}$ and was evaluated by particle size change. The particle size of the emulsions was determined by the median diameter of the volume (VMD).

\section{Emulsion stability index of $A$. oerfota.}

The change in emulsion particle size measured emulsification stability after acceleration check. The emulsion stability index (ESI) was determined using an equation according to the PHRC grading system:

$\mathrm{ESI}=\mathrm{d} 0.5 \mathrm{as}$ prepared $+(\mathrm{d} 0.53$ days@60C-d0.5as prepared $)+(\mathrm{d} 0.57$ days @60C-d0.5as prepared $)$ 


\section{RESULTS AND DISCUSSION}

\section{Moisture content}

Table 2 shows that with an average value of $12.45 \%$, the moisture content of $A$. oerfota gum obtained from the location of Senga varied between 11.8-13.1\%. These findings are the same as those of the samples obtained from the area of Wadel Hadad (11.8-13.4\%) with an average value of $12.60 \%$, as shown in Table 3 . These findings indicate higher levels of moisture compared to $4.60 \%$, which is supported by Karamalla (1999). These findings comply with the moisture content of The Sudanese Standards (not more than 15\%).

\section{Ash content}

Tables 2 and 3 reveal that the ash percentage of $A$. oerfota gum is within the range of (1.12-1.40\%). The average is $1.26 \%$, which is almost the ash content of the $A$. oerfota gum reported by Anderson (1976) and Karamalla (1999), which was found to be $1.54 \%$ and $1.03 \%$ respectively. These results are lower than the results reported by Osman (1993) in the A. senegal gum study collected from different locations in Sudan, with an average ash content of $3.6 \%$. Results were also lower than those reported for A. senegal by Karamalla (1998), Omer (2006), Abdelrahman (2008) and Younes (2009), 3.77\%, $3.27 \%, 3.32 \%$ and $4.89 \%$ respectively.

\section{pH value}

The average Senga value in Tables 2 and 3 show no significant variation between the two locations (4.88-5.26) and Wadel Hadad (4.55-5.28). The A. oerfota gum is therefore of low acidity nature. These results are lower than the results recorded by Karamalla (1999), namely 3.5. Compared to A. senegal gum, the findings are close to 4.66 as reported by Karamalla et al. (1998) and 4.78 reported by Younes (2009).

\section{Specific optical rotation}

Tables 2 and 3 indicate that $A$. oerfota gum's basic optical rotation is +65 to +80 , with an average value of $72.5 \%$. These findings align with the outcome stated by Karamalla (1999), which was +64.16. Compared to $A$. senegal, Anderson (1977), Osman (1993), Vavdevelde and Fenyo (1985) reported laboratory values of $-30^{\circ},-29^{\circ}$ to $31^{\circ}$ and $-29^{\circ}$ to $-34.4^{\circ}$, respectively. But research by Hassan (2000), Siddig et al. (2005), Omer (2006), Younes (2009), which were $+40^{\circ}$ to $+62^{\circ},+45^{\circ},+49.4^{\circ}$, and $+52^{\circ}$ respectively, show a little increase compared to the results calculated, corresponding to A. seyal.

\section{Cations composition}

Using the electronic scanning microscope process, cationic composition was studied. Tables 4 and 5 show that calcium had the highest value among the cations studied at the location of Wadel Hadad, followed by silicon, potassium, iron, titanium, and strontium. Tables 6 and 7 show that calcium, potassium, silicon, sulfur, and iron are the cation composition of the Senga location.

\section{Viscosity}

Acacia oerfota gum viscosity was measured using the U-tube Ostwald viscometer. The results were found to be in the 3.94-10 $\mathrm{cm}^{3} \mathrm{~g}^{-1}$ range, as shown in Figure 2. Their similarity to the Gummiferae series illustrates these findings. They are distinguished by their low viscosity (Anderson and Herbich 1963, 1966). These findings are lower than the $A$. senegal $\left(9.7-26.5 \mathrm{~cm}^{3} \mathrm{~g}^{-1}\right)$ which was obtained by Al-Assaf et al. (2005). For A. seyal, Hassan et al. (2005) reported $11.9-17.6 \mathrm{~cm}^{3} \mathrm{~g}^{-1}$.

Calculations of the Huggin coefficient $(\mathrm{k})$ and $(\alpha)$ using the Mark-Houwink equation were made based on the relationship of viscometer-determined intrinsic viscosity to GPC-MALLS-determining molecular mass and resulted in 0.86 and 0.0136 respectively.

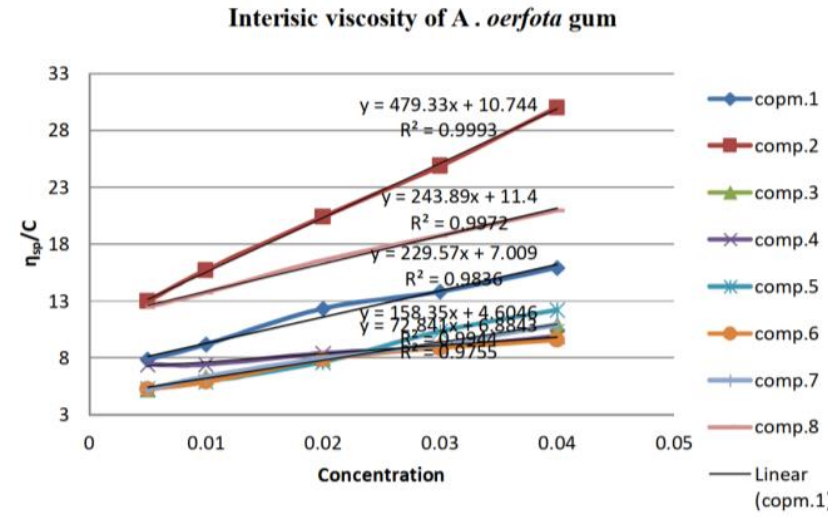

Figure 2. The intrinsic viscosity of six composite sample of Acacia oerfota gum.

Table 2. Physicochemical properties of Acacia oerfota gum of Senga location.

\begin{tabular}{llcccc}
\hline No. & S. name & $\begin{array}{c}\text { Moisture } \\
\text { \% }\end{array}$ & $\begin{array}{c}\text { Ash } \\
\text { \% }\end{array}$ & pH & $\begin{array}{c}\text { S.O. } \\
\text { Rotation }\end{array}$ \\
\hline 1 & Sample.1 & 12.37 & 1.10 & 4.88 & +80 \\
2 & Sample. 2 & 13.65 & 1.12 & 5.09 & +70 \\
3 & Sample. 3 & 11.23 & 1.16 & 4.97 & +65 \\
4 & Sample.4 & 11.67 & 1.24 & 5.15 & +60 \\
5 & Sample.5 & 13.46 & 1.22 & 4.90 & +80 \\
6 & Sample.6 & 12.90 & 1.34 & 5.22 & +60 \\
7 & Sample.7 & 11.13 & 1.26 & 5.09 & +80 \\
8 & Sample. 8 & 12.5 & 1.28 & 5.03 & +80 \\
9 & Sample.9 & 12.67 & 1.22 & 5.13 & +65 \\
10 & Sample.10 & 11.98 & 1.40 & 5.26 & +65 \\
11 & Sample.11 & 12.79 & 1.30 & 5.20 & +75 \\
12 & Sample.12 & 11.21 & 1.30 & 5.08 & +65 \\
13 & Sample.13 & 12.02 & 1.49 & 5.26 & +80 \\
14 & Sample.14 & 12.25 & 1.29 & 5.21 & +80 \\
15 & Sample.15 & 11.98 & 1.26 & 5.18 & +80 \\
16 & Comp.1 & 12.35 & 1.26 & 4.90 & +70 \\
17 & Comp.2 & 12.47 & 1.27 & 5.15 & +65 \\
18 & Comp.3 & 12.33 & 1.24 & 5.16 & +75 \\
19 & Comp.4 & 12.16 & 1.30 & 5.05 & +70 \\
Ranges & & $11.8-13.1$ & $1.12-1.40$ & $4.88-5.26$ & $+65-+80$ \\
\hline
\end{tabular}


Table 3. Physicochemical properties of Acacia oerfota gum of Wadel Hadad location.

\begin{tabular}{llcccc}
\hline No. & S. name & $\begin{array}{c}\text { Moisture } \\
\text { \% }\end{array}$ & $\begin{array}{c}\text { Ash } \\
\text { \% }\end{array}$ & pH & $\begin{array}{c}\text { S.O. } \\
\text { Rotation }\end{array}$ \\
\hline 1 & sample.16 & 12.8 & 1.60 & 4.55 & +75 \\
2 & sample.17 & 12.2 & 1.86 & 4.94 & +65 \\
3 & sample.18 & 12.5 & 1.56 & 4.96 & +65 \\
4 & sample.19 & 12.7 & 1.58 & 4.65 & +70 \\
5 & sample.20 & 13.1 & 1.83 & 5.02 & +70 \\
6 & sample.21 & 12.2 & 1.43 & 4.88 & +80 \\
7 & sample.22 & 12.6 & 1.62 & 4.88 & +65 \\
8 & sample.23 & 12.9 & 1.61 & 4.94 & +80 \\
9 & sample.24 & 13.4 & 1.27 & 4.97 & +75 \\
10 & sample.25 & 11.9 & 1.83 & 4.60 & +75 \\
11 & sample.26 & 12.6 & 1.40 & 4.90 & +75 \\
12 & sample.27 & 11.8 & 1.53 & 4.90 & +70 \\
13 & sample.28 & 12.4 & 1.16 & 5.28 & +75 \\
14 & sample.29 & 12.6 & 1.20 & 4.87 & +70 \\
15 & sample.30 & 13.0 & 1.65 & 4.90 & +75 \\
16 & Comp.5 & 12.2 & 1.60 & 4.83 & +80 \\
17 & Comp.6 & 12.6 & 1.63 & 4.90 & +75 \\
18 & Comp.7 & 12.9 & 1.31 & 4.88 & +65 \\
19 & Comp.8 & 12.5 & 1.65 & 4.86 & +70 \\
Ranges & & $11.8-13.4$ & $1.18-1.31$ & $4.55-5.28$ & $+65-+80$ \\
\hline
\end{tabular}

Table 4. The cationic composition of A. oerfota gum-Wadel Hadad location.

\begin{tabular}{lll}
\hline Element & Result & Unit \\
\hline $\mathrm{Ca}$ & 0.287 & $\%$ \\
$\mathrm{~K}$ & 0.131 & $\%$ \\
$\mathrm{Fe}$ & 0.010 & $\%$ \\
$\mathrm{Sr}$ & 0.004 & $\%$ \\
\hline
\end{tabular}

Table 5. The cations composition $\%$ to the total amount of cations included in A. oerfota gum of Wadel Hadad location

\begin{tabular}{lcccccc}
\hline Element & $\mathbf{C a}$ & $\mathbf{S i}$ & $\mathbf{K}$ & $\mathbf{F e}$ & $\mathbf{T i}$ & $\mathbf{S r}$ \\
\hline $\begin{array}{l}\text { Percentage } \\
\%\end{array}$ & 58.783 & 18.670 & 16.248 & 3.955 & 1.285 & 1.099 \\
\hline
\end{tabular}

Table 6. The cationic composition of A. oerfota of Senga location

\begin{tabular}{lll}
\hline Element & Result & Unit \\
\hline $\mathrm{Ca}$ & 0.242 & $\%$ \\
$\mathrm{~K}$ & 0.145 & $\%$ \\
$\mathrm{Sr}$ & 0.005 & $\%$ \\
$\mathrm{~S}$ & 0.002 & $\%$ \\
$\mathrm{Fe}$ & 0.001 & $\%$ \\
\hline
\end{tabular}

Table 7. The cationic composition $\%$ to the total amount of cations included in Acacia oerfota gum of Senga location.

\begin{tabular}{lccccc}
\hline Element & Ca & K & Sr & S & Fe \\
\hline Result & 62.633 & 19.628 & 12.729 & 3.549 & 1.461 \\
\hline
\end{tabular}

\section{Calorific value}

Table 8 shows that the calorific values of the A. oerfota gum are like the calorific values of the gums and were approximately $4 \mathrm{Kcal} / \mathrm{g}$. This calorific value is very low, so after evaluating the toxicity value, the $A$. oerfota gum is very suitable for use as a food additive.

\section{Nitrogen and protein content}

The average nitrogen and protein content of A. oerfota gum samples was higher than the nitrogen and protein content of $A$. senegal and $A$. seyal gum. The average nitrogen and protein content of $A$. oerfota gum was found to be 0.53 and $3.28 \%$ respectively in Table 9 . Anderson (1977) estimated that $A$. senegal gum's nitrogen content was $0.29 \%$ and $0.14 \%$ for $A$. seyal. Osman (1993) reported a nitrogen content of $0.31 \%$ and a protein content of $2.4 \%$ for $A$. senegal gum. Hassan et al. (2005) reported that $A$. seyal's protein content had a mean value of $0.96 \%$. Younes (2009) estimated a nitrogen content of $0.35 \%$ and a protein content of $2.3 \%$ for A. senegal. A. senegal's nitrogen content was analyzed by Idris et al. (1998), from various age groups and locations. The range between $0.22-0.39 \%$ and the protein content was therefore found to vary, 1.5$2.6 \%$.

\section{Equivalent weight and total uronic acid}

Table 10 revealed that $A$. oerfota has an acid equivalent weight and total uronic acid percentages of gum (29415357) and (3.62-6.60) of A. oerfota, and A. oerfota's rule acidity (1993), while Osman (1993) estimated that the acid equals 1040 , while the uronic acid is $17 \%$.

Table 9. Nitrogen and protein content of Acacia oerfota gum

\begin{tabular}{lccc}
\hline location & Sample code & $\begin{array}{c}\text { Nitrogen } \\
\text { content }\end{array}$ & Protein \% \\
\hline Wadel Hadad & Comp.1 & 0.49 & 3.06 \\
& Comp.2 & 0.63 & 3.94 \\
& Comp.3 & 0.51 & 3.11 \\
& Comp.4 & 0.49 & 3.06 \\
Senga & & & \\
& Comp.5 & 0.35 & 2.19 \\
& Comp.6 & 0.77 & 4.81 \\
& Comp.7 & 0.43 & 2.71 \\
& Comp.8 & 0.42 & 2.63 \\
\hline
\end{tabular}

Table 8. The calorific values of gum Acacia oerfota gum.

\begin{tabular}{|c|c|c|c|c|c|c|c|}
\hline Sample name & $\begin{array}{l}\text { Sample } \\
\text { location }\end{array}$ & $\begin{array}{l}\text { Sample } \\
\text { weight }\end{array}$ & $\begin{array}{c}\text { bag Cal. value } \\
\mathrm{J} / \mathrm{g}\end{array}$ & $\begin{array}{c}\text { Cross cal. } \\
\text { Value }\end{array}$ & $\begin{array}{l}\text { Net Cal. value } \\
\mathrm{J} / \mathrm{g}\end{array}$ & $\begin{array}{l}\text { net.Cal.value. } \\
\mathrm{cal} / \mathrm{g}\end{array}$ & $\begin{array}{c}\text { Cal Value } \\
\text { Kcal/g }\end{array}$ \\
\hline A.Oerfota gum & Senga & 0.5189 & 46463 & 15805 & 17024 & 4067 & 4.067 \\
\hline A.Oerfota gum & Wadel Hadad & 0.5066 & 46463 & 15596 & 16829 & 4020 & 4.020 \\
\hline
\end{tabular}




\section{Color Gardner and Tannin content}

The color Gardner of gum Acacia oerfota is 0.1 for Senga composite sample and 0.2 for Wadel Hadad composite sample. Table 11 shows that the values increase with time ( 24 hours and 48 hours) due to oxidation of polyphenol. Tannin content was calculated according to Kjeldahl method. The two composite samples have tannin content of about 268.0 and $292.1 \mathrm{mg} / \mathrm{g}$, respectively.

\section{Determination of number average molecular weight by Osmotic pressure}

The results obtained for gum Acacia oerfota are consistent with the observation that Gummiferae series typically possess a high molecular weight. Figure 3 shows the values of number average molecular weight $(\mathrm{Mn})$ of gum Acacia oerfota obtained by osmotic pressure are 1.68 $\times 10^{5}$ and $1.80 \times 10^{5} \mathrm{~g} / \mathrm{Nol}$ for the two total composites of two locations. These values were lower than the values obtained by gel permeation chromatography $6.23 \times 10^{5}$ and $9.59 \times 10^{5}$. The difference in the results is probably due to the differences between the two techniques. The values of number average molecule weight $(\mathrm{Mn})$ of A. oerfota gum is not more variable than that of A. senegal 2-3 $\times 10^{5}$ (Osman, et.al.1993).

Table 10. Equivalent weight and uronic acid of Acacia oerfota gum.

\begin{tabular}{lccc}
\hline Location & Sample & Acid eq. weight & Uronic acid \% \\
\hline Wadel Hadad & comp.1 & 3409 & 5.69 \\
& comp.2 & 3571 & 5.43 \\
& comp.3 & 3333 & 5.82 \\
& comp.4 & 2941 & 6.60 \\
Senga & & & \\
& comp.1 & 5357 & 3.62 \\
& comp.2 & 3846 & 5.04 \\
& comp.3 & 3192 & 6.08 \\
& comp.4 & 3409 & 5.69 \\
\hline
\end{tabular}

Table 11. Color and tannin value of Acacia oerfota gum.

\begin{tabular}{lllllll}
\hline \multicolumn{1}{c}{ Location } & $\begin{array}{c}\text { off } \\
\text { Hue }\end{array}$ & $\mathbf{L}^{*}$ & $\mathbf{a}^{*}$ & $\mathbf{b}^{*}$ & Gardner & $\begin{array}{c}\text { Tannin } \\
(\mathbf{p p m})\end{array}$ \\
\hline & & & & & & \\
$\begin{array}{l}\text { After 3 hours } \\
\text { Senga }\end{array}$ & 0 & 99.3 & -0.02 & 0.84 & 0.1 & 268.0 \\
Wadel hadad & 0 & 98.71 & -0.05 & 1.37 & 0.2 & 292.1 \\
& & & & & & \\
After 24 hours & & & & & & \\
Senga & 0 & 99.6 & -0.11 & 0.86 & 0.1 & 268.0 \\
Wadel hadad & 0 & 99.14 & -0.08 & 1.46 & 0.3 & 292.1 \\
& & & & & & \\
After 48 hours & & & & & & \\
Senga & 0 & 98.04 & -0.07 & 2.09 & 0.3 & 268.0 \\
Wadel hadad & 0 & 97.83 & -0.17 & 2.63 & 0.3 & 292.1 \\
& & & & & & \\
\hline
\end{tabular}

\section{Infrared spectroscopy (FTIR)}

Acacia oerfota defined different functional classes in the entire spectrum (FTIR) (Figure 4). Glucurónic acid covers a wide range of $3600-3000 \mathrm{~cm}-1$ in an O-H stretch, which is the most prominent and strongest band. Simultaneously, the belt displays a vibration of $\mathrm{C}=\mathrm{O}$ stretching in the center of the spectrum in $1730 \mathrm{~cm}-1$. The deep stretching vibration occurs with $1031 \mathrm{~cm}-1$ hydroxyl grouping of composite sugars with phenol like $\mathrm{C}-\mathrm{O}$ band. Aliphatic $\mathrm{C}-\mathrm{H}$ strain and still vibration are respectively the cause of the bending weakness of the beak at $2929 \mathrm{~cm}-1$ with approximately $1,500 \mathrm{~cm}-1$.

\section{Rheology of the gum}

In two different concentrations, $25 \%$ and $50 \%$, the Rheological activity of $A$. oerfota gum was researched. $A$. oerfota gum displays Newtonian behavior according to Figures 5, 6 and 7 (viscosity is constant with increasing applied shear rate), and the molecules maintain initial viscosity to remove the applied stress (Braun and Rosen 2000).

\section{The dynamic rheology}

Figure 8 indicates that $A$. oerfota gum's loss modulus $\left(\mathrm{G}^{\prime \prime}\right)$ was higher than the storage modulus $\left(\mathrm{G}^{\prime}\right)$ and they do not cross, so $A$. oerfota gum is not viscous, elastic, or viscoelastic.

The frequency sweep offers gel strength information, where a high $\mathrm{G}$ curve slope indicates low strength, and a small slope indicates high strength (Mezger 2002). Both gums exhibited similar gel strength. As the $G^{\prime}$ modulus is frequency-dependent, but the $\mathrm{G}^{\prime}$ modulus depends on the frequency square (Barnes et al. 2001). $G^{\prime}$ at higher frequencies becomes more important. $\mathrm{G}^{\prime \prime}$ is greater than $\mathrm{G}^{\prime}$ compared to Acacia tortilis, and then Acacia tortilis has viscose properties at a lower frequency. Systematically, with increasing frequency over a wide spectrum, the Acacia tortilis solution transitions from viscose to elastic properties (Mezger 2002). Above critical frequency, Acacia tortilis forms solid gels (0.5 HZ).

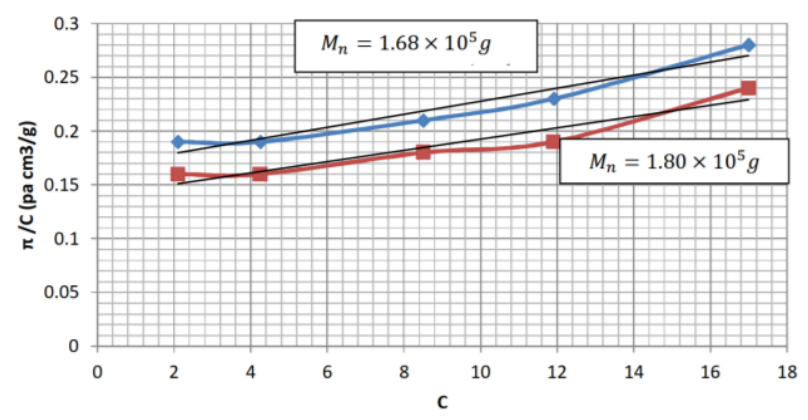

Figure 3. A plot of G versus C for Acacia oerfota gum at $25 \mathrm{C}$. 

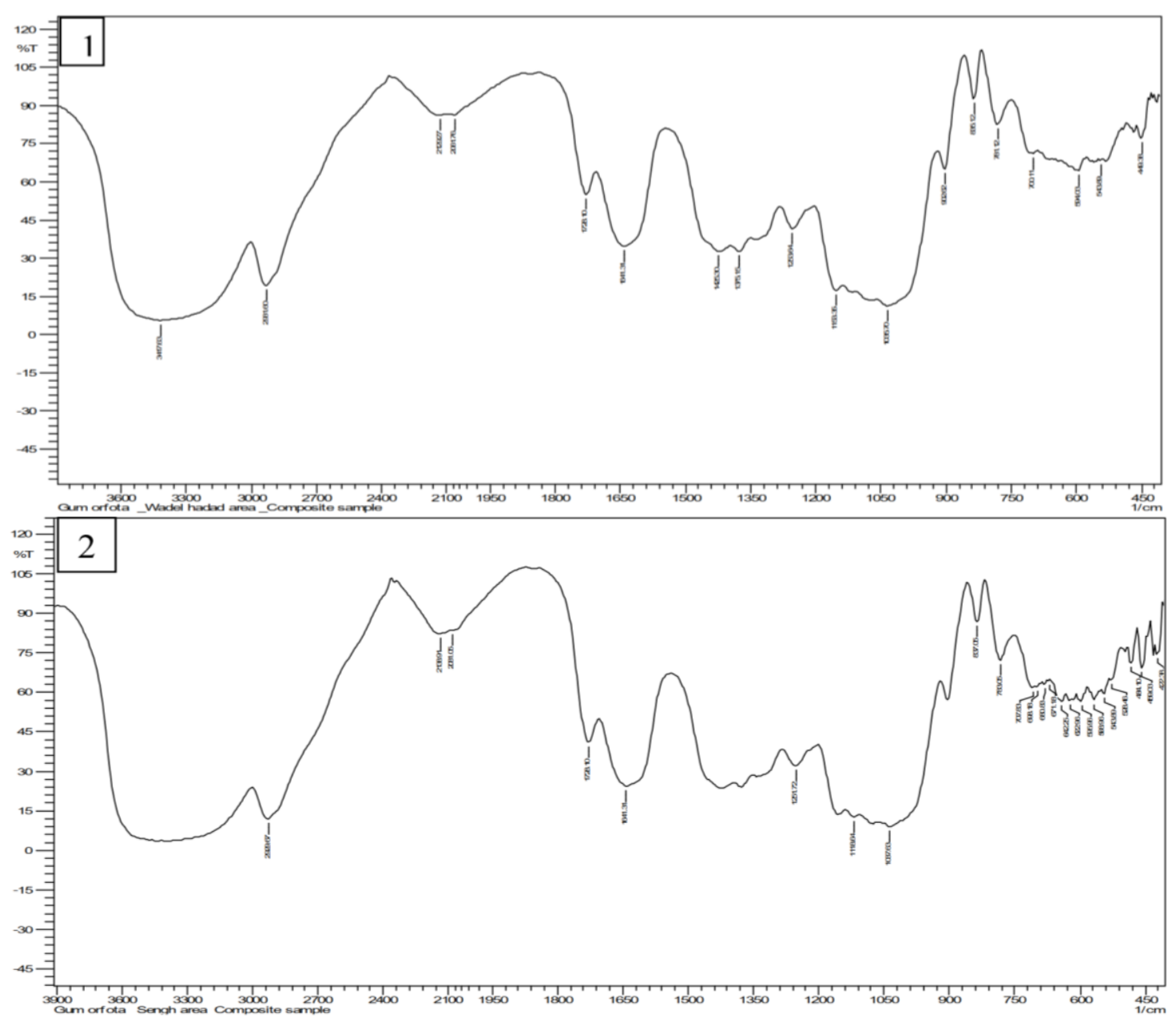

Figure 4. FTIR of composite sample of Acacia oerfota from (1) Senga location, (2) Wadel Hadad location.

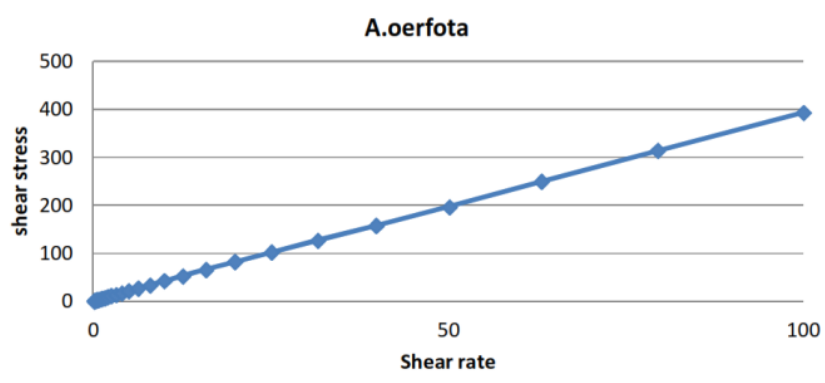

Figure 5. Shear rate versus shear stress of Acacia oerfota gum.

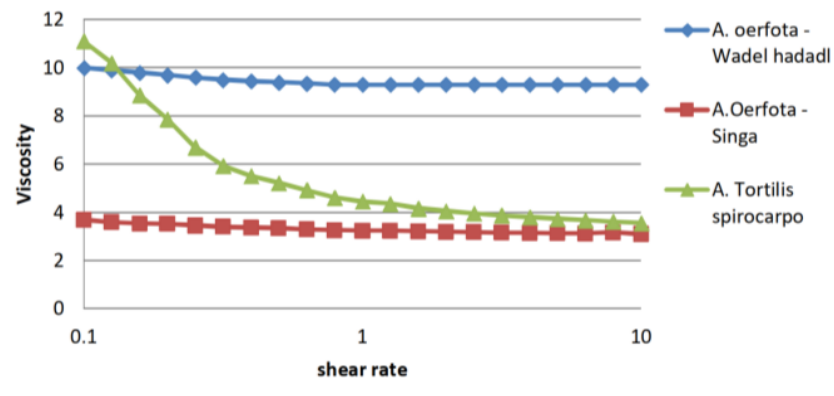

Figure 6. Viscosity profile of Acacia gum emulsions with shear rate-conc. $25 \%$.

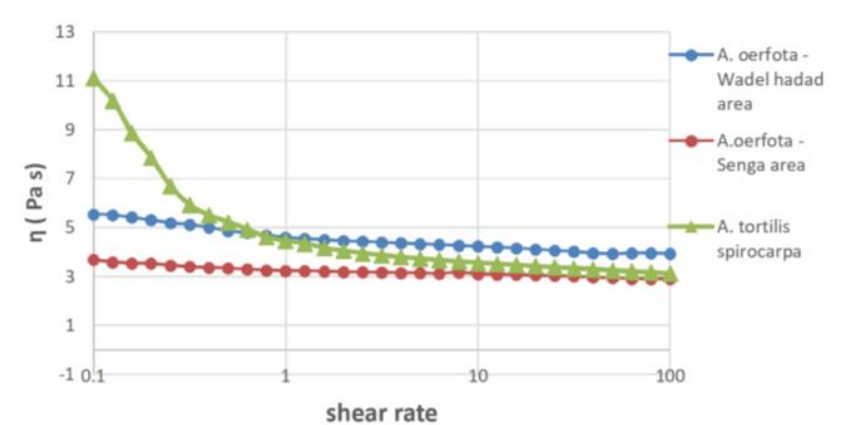

Figure 7. Viscosity profile of Acacia gums emulsions with shear rate-conc. $50 \%$.

\section{Gel permeation chromatography (GPC MALLS)}

GPC-MALLS with on-line monitoring used RI, LS, and UV absorbance detectors. The GPC-MALLS result for $A$. oerfota and A. senegal gum are shown in Table 12.

\section{GPC MALLS-RI}

RI profiles of $A$. oerfota and A. senegal gums are shown in Figure 9. The profile consists of three AGP, AG and GP highlights. In the first AGP peak, the situation is very different. In contrast to A. senegal gum AGP, the mass percent of the AGP of the two A. oerfota gums are very poor. 
Table 12. The GPC-MALLS result for Acacia oerfota and A senegal gum.

\begin{tabular}{llll}
\hline Function/sample & \multicolumn{2}{l}{ A. oerfota.1 A. oerfota.2 } & A. senegal \\
\hline Mw whole gum (x10 & 6.23 & 9.59 & 5.95 \\
\% Mass recovery & 108.685 & 105.78 & 113.97 \\
Rg (whole gum)/nm & 178 & 178 & $50.6(6 \%)$ \\
Mw AGP & 4.77 & 14.19 & 1.68 \\
$\%$ mass (AGP) & 1.11 & 0.84 & 17.73 \\
Rg-AGP & 50 & 187 & $38 .(3 \%)$ \\
Mw (AG+GP) (x10 10 & 5.76 & 8.24 & 3.59 \\
$\%$ mass (AG+GP) & 98.89 & 99.16 & 82.27 \\
\end{tabular}

\section{GPC MALLS-LS}

Light scattering profiles for AGP and AG of the two A. oerfota and A. senegal gums are shown in Figure 10. The first peak illustrates the substantial difference between the molecular weights of the protein components of Arabinogalactan in the gums of $A$. oerfota and A. senegal. In contrast, the molecular weight of the Arabinogalactan protein in A. oerfota is very low. However, A. oerfota's AG+GP molecular weight is higher than that of $A$. senegal gum.
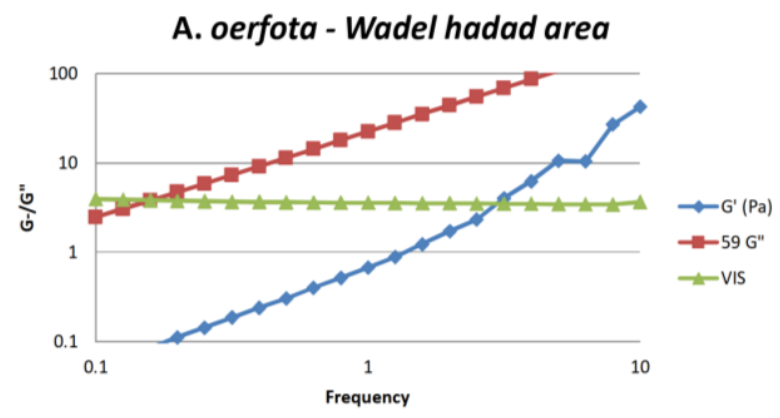

Figure 8. The effects of frequency on G' and G".

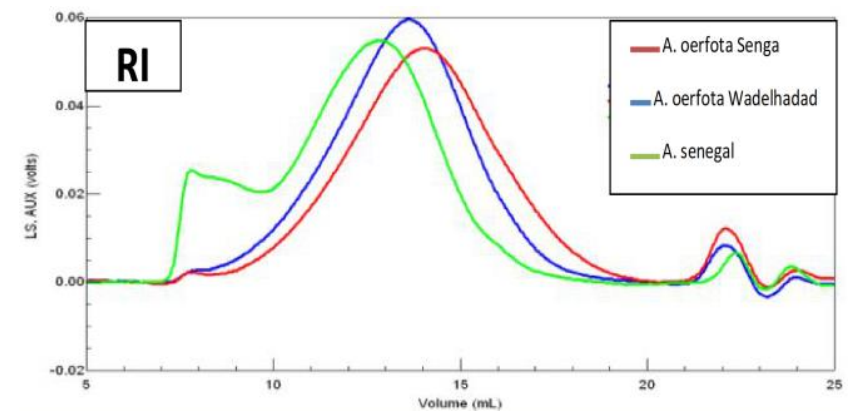

Figure 9. The RI of two Composite samples of Acacia oerfota and A. senegal.

\section{GPC MALLS-UV}

The UV and GPC profiles for A. oerfota and A. senegal gums are shown in Figure 11. Clearly, they demonstrate a large difference in protein content. In contrast to that of $A$. senegal gum, the AGP signal of $A$. oerfota gum is very weak. However, the AG and GP signals are nearly identical, suggesting a similar composition of proteins.

\section{The emulsification properties of $A$. oerfota gum}

Good emulsions are characterized by a narrow band and a wide particle diameter of between 0.1 and 1 micron. The emulsification properties of $A$. oerfota gum have been analyzed by assessing the emulsion particle size at zero and after 3 and 7 days of incubation at $60^{\circ} \mathrm{C}$.

The position had no major impact on the emulsification properties of $A$. oerfota gum, as seen in Table 13. The mean weighted surface $\mathrm{D}(3,2)$ and the mean weighted volume $\mathrm{D}(4,3)$ increased, and the percentage of the duration decreased with time.

Compared to $\mathrm{D}, \mathrm{D}(4,3)$ is more susceptible to the presence of large particles in an emulsion $(3,2)$. Thus, $\mathrm{D}(4,3)$ is more susceptible to the flocculation phenomenon. As all emulsions display large droplets, this could explain the higher value of $\mathrm{D}(4,3)$ relative to $\mathrm{D}(3,2)$. According to the emulsion stability index value used as a criterion to determine the grade of the gum sample, the gum is built to be grade 3 .
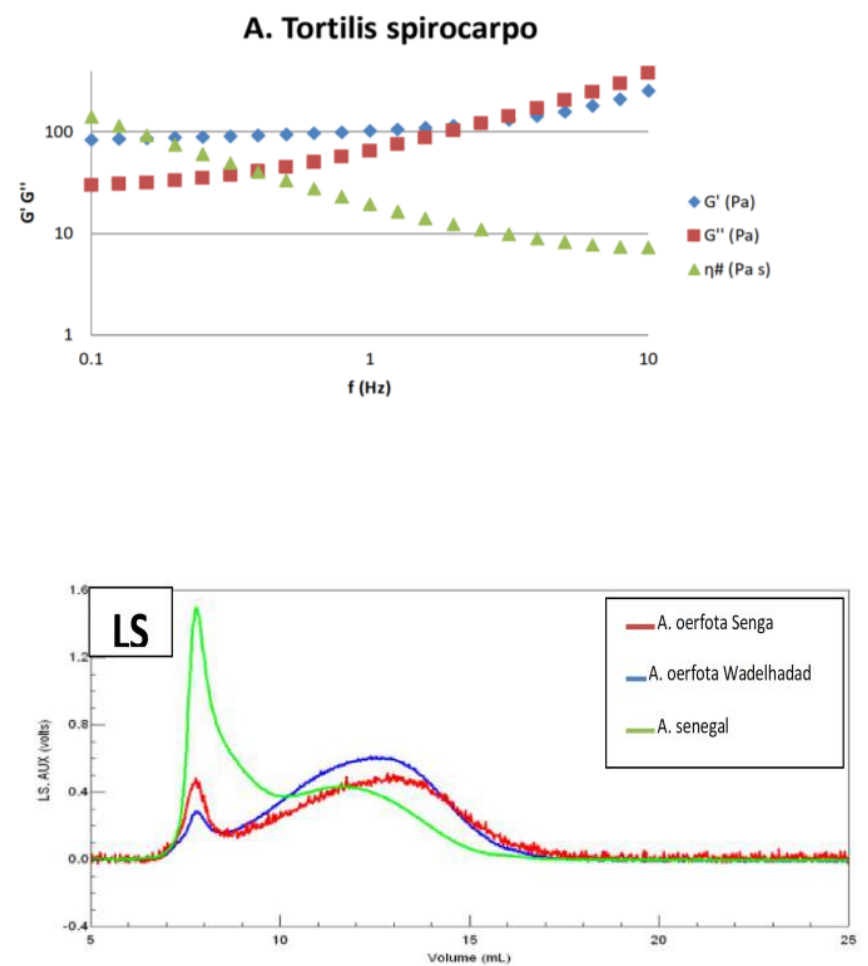

Figure 10. The LS of two composite samples of Acacia oerfota and $A$. senegal. 


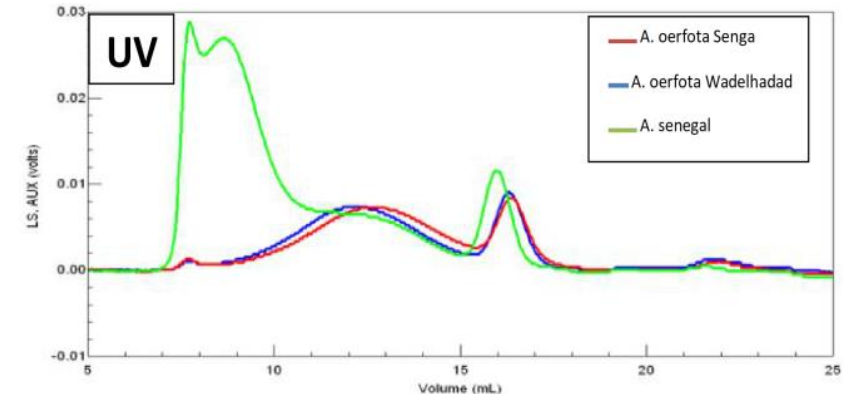

Figure 11. The UV of two Composite samples of Acacia oerfota and A. senegal.

Figure 12 shows more variable particle sizes spread over a wide range of microns (0.1-10) and most particle diameter sizes are high, suggesting $A$. oerfota gum emulsion instability (Billmeyer 1971). A standard bimodal droplet size distribution with a pronounced shoulder representing two droplet groups with the small and largest diameter was seen in the emulsions. In the range of good emulsion particle size, it decreased with time according to the phase of flocculation and coalescence. The instability of the emulsions was confirmed by the pig droplet size and low viscosity $\left(3.411 .4 \mathrm{~cm}^{3} \mathrm{~g}^{-1}\right)$ and pig rate of gyration of Acacia oerfota gum.

Figure 13 shows a high polydispersity index value (percent span) for fresh emulsions and after incubation at $60 \mathrm{oC}$ for 3 and 7 days, respectively. Two positions suggest low droplet size uniformity. These values indicate emulsion instability by reducing the amount of protein that is associated with the emulsion droplet surface.

Relevant surface area $\left(\mathrm{m}^{2} / \mathrm{g}\right)$ of cumulative droplet distributions of (D.5, D.9, >1 micron and >2 micron) are shown in Figure 14. The results clearly showed that drastic changes in emulsions were observed during incubation at $60 \mathrm{oC}$ for 3 and 7 days. Emulsion instability has also increased by reducing the region of $\mathrm{D}(0.5)$ to less than $6 \%$ and increasing the size of droplet particles with a diameter of more than one micron to more than $80 \%$.
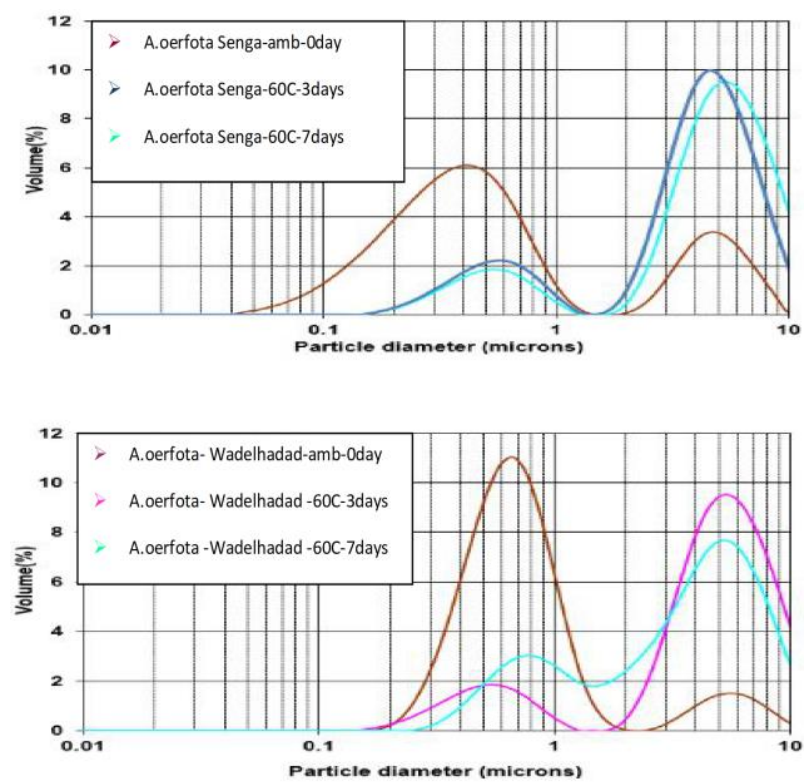

Figure 12. The emulation particle size profile of Acacia oerfota from two locations.

span \%

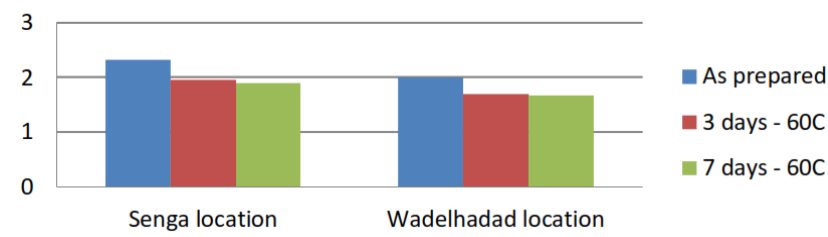

Figure 13. The span\% of Acacia oerfota gum from two locations

Table 13. The emulsification properties of Acacia oerfota gum.

\begin{tabular}{lcccccc}
\hline & & Senga location & & \multicolumn{3}{c}{ Wadel Hadad location } \\
\hline \multicolumn{1}{c}{ Character } & As prepared & After 3 days & After 7 days & As prepared & After 3 days & After 7 days \\
\hline $\mathrm{D}(3,2)$ & 0.674 & 1.81 & 1.99 & 0.364 & 2.08 & 1.79 \\
$\mathrm{D}(4,3)$ & 1.26 & 4.43 & 4.34 & 1.56 & 5.42 & 4.46 \\
span\% & 2.32 & 1.95 & 1.9 & 1.98 & 1.74 & 1.68 \\
$\mathrm{Dx}(10)$ & 0.40 & 0.69 & 0.74 & 0.166 & 0.63 & 0.58 \\
$\mathrm{Dx}(20)$ & 0.49 & 0.96 & 1.16 & 0.238 & 2.95 & 2.17 \\
$\mathrm{Dx}(50)$ & 0.72 & 4.26 & 4.08 & 0.477 & 3.23 & 4.42 \\
$\mathrm{Dx}(80)$ & 1.1 & 7.3 & 6.91 & 3.51 & 8.1 & 6.63 \\
$\mathrm{Dx}(90)$ & 2.1 & 8.98 & 8.49 & 5.4 & 9.71 & 7.98 \\
Grade & 3 & 3 & 3 & 3 & 3 & 3 \\
\hline
\end{tabular}


$D(0.5)$

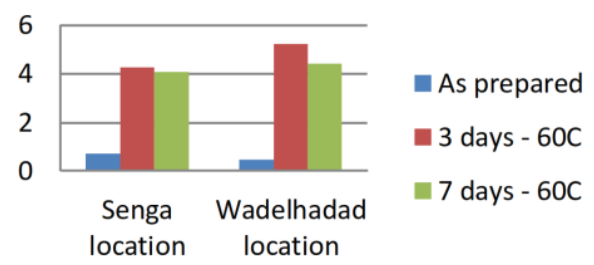

$>1$ microns

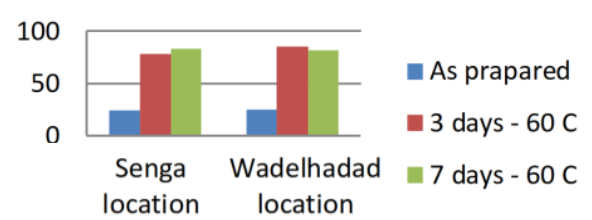

$D(0.9)$

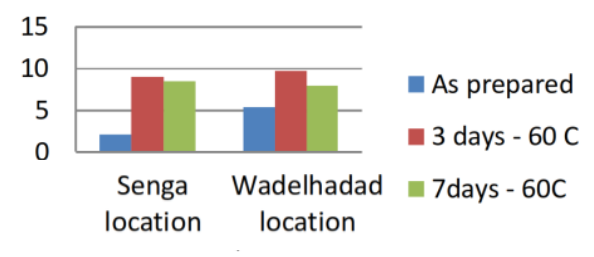

$>2$ microns

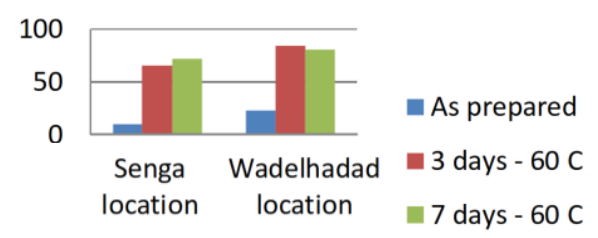

Figure 14. The volume-weighted mean diameter of Acacia oerfota gum emulsion from two locations

In conclusion, Acacia oerfota gum displays physicochemical properties that indicate its similarity to the sequence of Gummiferae. The rheology of A. oerfota solution gum indicates that Newtonian fluid is formed by the gum. The modulus of loss of A. oerfota gum is larger than the module for storage. A. oerfota gum's molecular weight varies between $(6.23 \times 105$ and $9.59 \times 105 \mathrm{~g} / \mathrm{mole})$ with the same gyration radius. In contrast to A. senegal, the Arabinogalactan protein of $A$. oerfota gum has just $1 \%$ mass and low molecular weight. A. oerfota gum forms an unstable emulsion that is weak.

\section{REFERENCES}

Abdel Nour HO. 1999. Gum Arabic in Sudan: Production and socioeconomic aspect. International Expert Meeting on Medicinal, Culinary and Aromatic Plants in the Near East, Cairo (Egypt), 19-21 May 1997.

Abdelrahman MA. 2008. Characterization, thermodynamic, denaturation and molecular expansion properties of A. seyal, A. senegal and A. Polyacantha. [Doctoral dissertation, Ph. D Thesis]. Chemistry Department, Faculty of Science, Sudan University of Science and Technology, Sudan.

Al-Assaf S, Phillips GO, Williams PA. 2005. Studies on Acacia exudate gums: part II. Molecular weight comparison of the Vulgares and Gummiferae series of Acacia gums. Food Hydrocoll 19 (4): 661-667.

Anderson DMW, Cree GM. 1968. Studies on uronic acid materials: Part XXVII. The structure of the gum from Acacia nubica Benth. Carbohydr Res 6 (4): 385-403.

Anderson DMW, Herbich MA. 1963. Studies on uronic acid materials. Part VI. The variation in composition and properties of gum nodules from Acacia seyal del. J Chem Soc: 1-6.

Anderson DMW, Stoddart JF. 1966. Studies on Uronic Acid Materials. Part XV. The use of molecular-sieve chromatography in studies on Acacia senegal gum (Gum Arabic). Carbohydr Res 2: 104-114.

Anderson DMW. 1976. Analytical method for identification of gum exudates from Acacia species fourth international symposium. Gum and Hydro-Soluble Natural Vegetal Colloids, $5^{\text {th }}-8^{\text {th }}$ November, France.

Anderson DM. 1977. Water-soluble plant gum exudates. Gum Arabic. Porc Biochem 12: 24.25.

AOAC. 1984. Official Methods of Analysis. Association of Official Analytical Chemists, fourth Edition. Washington D.C.
Australian National Herbarium. Retrieved October 24, 2013.

Barnes HA, Hutton JF, Walters K. 2001. An Introduction to Rheology. Elsevier Science Pub Co.

Billmeyer FW. 1971. Textbook of Polymer Science. Interscience Publisher, New York.

Braun DB, Rosen MR. 2000. Rheology Modifiers Handbook-Practical Use and Application. William Andrew Publishing, Norwich, New York, USA.

Clemens J, Jones PG, Gilbert NH. 1977. Effect of seed treatments on germination in Acacia. Australian Journal of Botany, 25(3), 269-276.

Elamin HM. 1973. Sudan Acacias. Publishing Section Information Department, Sudan.

Elamin HM. 1990. Trees and shrubs of Sudan. [Dissertation]. University of Khartoum, Sudan.

Elmer P. 1994. Analytical Methods for Atomic Absorption Spectrometry. The Perkin Elmer Corporation, USA.

El-Gazali GE. 1985. The Pollen Flora in Sudan, with Special Reference to Pollen Identification. John Willy \& Son Inc., London.

FAO. 1990. Specification for identity and purity of certain food additives. Food Nutrition Paper, FAO, Rome.

Gibreel HH. 2008. A taxonomic study on trees and shrubs of Alnour natural forest reserve, Blue Nile State. [Thesis] University of Khartoum, Sudan.

Graham HD. 1992. Stabilization of the Prussian blue color in the determination of polyphenols. J Agric Food Chem 40 (5): 801-805.

Hassan EA. 2000. Characterization and Fractionation of Acacia seyal Gum. [Dissertation]. University of Khartoum, Sudan.

Hassan EA, Al-Assaf S, Phillips GO, Williams PA. 2005. Studies on Acacia gums: Part III molecular weight characteristics of Acacia seyal var. seyal and Acacia seyal var fistula. Food Hydrocoll 19 (4): 669-677.

Idris OHM, Williams PA, Phillips GO. 1998. Characterisation of gum from Acacia senegal trees of different ages and locations using multidetection gel permeation chromatography. Food Hydrocoll 12 (4): 379-388.

Karamalla KA, Siddig NE, Osman ME. 1998. Analytical data for Acacia senegal var. senegal gum samples collected between 1993 and 1995 from Sudan. Food Hydrocoll 12 (4): 373-378.

Karamalla KA. 1999. Gum arabic production, chemistry and applications. University of Khartoum, Sudan.

Katayama T, Nakauma M, Todoriki S, Phillips GO, Tada M. 2006. Radiation-induced polymerization of gum arabic (Acacia senegal) in aqueous solution. Food Hydrocoll 20 (7): 983-989.

Mezger TG. 2002. The Rheology Handbook for Users of Rotational and Oscillatory Rheometers. Coating Compendia, Hannover.

Omer IE, Bakheit TN. 2006. Determination of tracer 240 SC (spinosad) and sumigold (esfenvalerate) residues in Acacia plant and soil. In Proceedings: The 75 th meeting of the national pests and diseases 
committee. Agricultural Research Corporation Conference Hall, Wad Medani (Sudan), September 2006.

Osman ME. 1993. Industrial uses of Gum Arabic (Acacia senegal) [Dissertation]. Salford University, UK.

Siddig NE, Osman ME, Al-Assaf S, Phillips GO, Williams PA. 2005 Studies on Acacia exudate gums, part IV. Distribution of molecular components in Acacia seyal in relation to Acacia senegal. Food Hydrocoll 19 (4): 679-686.

Singh G. 2004. Plant Systematics: An Integrated Approach. Science Publishers, New Delhi.
Smith GF, van Wyk AE, Luckow M, Schrire B. 2006. Conserving Acacia Mill. with a conserved type. What happened in Vienna?. Taxon 55 (1): 223-225

Thanukos. 2009. A name by any other tree. Evolution: Education and Outreach 2 (2): 303-309. DOI:10.1007/s 12052-009-0122-7.

USDA. 2008. ARS, National Genetic Resources program. Germplasm Resources Information Network, National Germplasm Resources Laboratory, Beltsville, MD.

Younes AAO. 2009. Physicochemical Studies on some Acacia Gum sand their Fractions. [Dissertation]. Sudan University of Science and Technology, Khartoum, Sudan. 